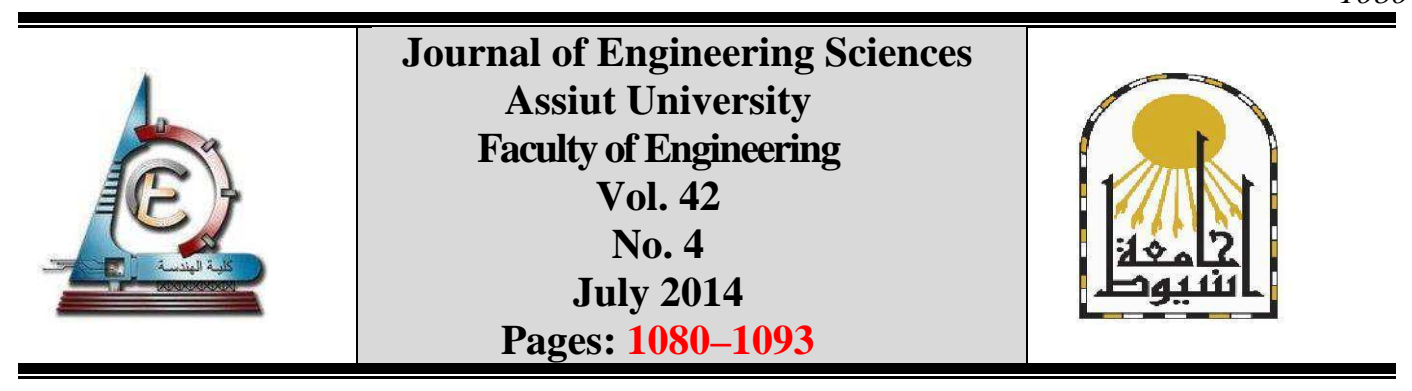

\title{
THE EFFECT OF USING INSULATION MATERIALS ON THE THERMAL PERFORMANCE OF RESIDENTIAL BUILDINGS IN CAIRO - EGYPT
}

\author{
Wael Ahmad Taha EL-Garhy \\ Environmental Studies and Researches Institute, University of Sadat City, Egypt
}

Received 19 May 2014; Revised 3 July 2014; accepted 15 July 2014

\begin{abstract}
Thermal confort accompanied with low energy in architecture is a major target of building researchers and designers worldwide. Obviously, any portion of energy that can be saved in this respect means protection for environment and maintenance of its resources and may be able to be directed to any other activities, if any.

Building energy consumption can be reduced through various systems such as air conditioning (AlC is a major building energy consumer), lighting, equipment, etc. In regions where energy is limited or scarce, air conditioning would have to be replaced by natural ventilation for the removal of the building heat load for thermal comfort.

Also, energy conservation issues are being more important in hot arid regions, especially because building are consuming more than $60 \%$ of electric energy generated and about $65 \%$ of this energy is consumed for cooling. There is a set of complex factors, which determines energy needs in building, such as solar radiation, type of A/C systems, building operation, and thermal characteristics of the building envelope ...etc. The parameters, which have effects on the thermal performance of walls and roofs, are the color, general construction, insulation and ventilation.

In the present decade the aim is to discuss the meaning of thermal comfort and advantage of energy efficient building materials design or selection. There are several ways to reduce the energy consumed in the human comfort process, but what is the most energy efficient or more energy saving of these ways. One of these is the insulation, which can be used for insulating walls and roofs, which are subjected to a large amount of the solar heat gain. The insulation of walls (especially west walls) and roofs is intended to maximize resident's thermal comfort and minimize energy consumption in housing.

The present study presents the effect of west wall insulation on the indoor thermal performance in order to select the suitable insulation which gives maximum thermal comfort, minimum cost and maximum energy saving. This work was done using actual field temperature measurements on actual location. The results provide suggestions to improve the building construction and indicate the importance of using the insulation materials in the wall construction in order to achieve thermal comfort characteristics for the occupants and also to reduce the consumed energy.
\end{abstract}


Keywords: Thermal mass - Thermal comfort - Insulation materials - Energy conservation Energy consumption.

\section{Introduction}

Al-Karagholi et al. [1] investigated different energy conservation techniques to decrease the air-conditioning load. The first objective when designing a house - the first full scale project built in Iraq - was to minimize the air conditioning load. From analysis, it is found that during the summer season the most influencing factor in decreasing the cooling load is window shading. 100\% shading will decrease the cooling load by $35 \%$ while using double glass will decrease the load by $23 \%$. The wall insulation saves $22 \%$ to $31 \%$ of the consumed energy during the summer season.

Chang and Guo [2] developed Tianjin energy efficiency standard for rural residential buildings in order to reduce energy consumption and carbon emissions and to improve poor indoor thermal comfort in existing rural residential buildings, Natural materials and appropriate passive techniques should be used to achieve the human thermal comfort goal with minimum energy consumption and lowest percentage of carbon emissions. The insulation passive technique for building envelope, determination of heat transfer coefficient, principle of choosing insulation materials for building envelope, energy efficiency standards of walls, windows, and roofs are analyzed and described.

Chwieduk [3] describes the traditional methods that used to conserve energy in residential buildings according to the main reasons for high heat gains. A discussion of some ideas of modern methods for energy conservation was done and recommendations for application of renewable energy were concluded. Using analysis of climatic data for a period of thirty years using psychometric chart, effective temperature chart, and isotherm chart to define "over heated periods" which requires sun protection.

Hai-xiang and Frederic [4] designed statistical methods and artificial intelligence methods to study the effect of many factors, such as ambient weather conditions, building structure and characteristics, the operation of sub-level components like lighting and HVAC systems, occupancy and their behavior on the energy performance in buildings, accurately implement prediction of building energy consumption is very difficult. To solve this problem, developed models included elaborate and simplified engineering methods.

Hall [5] (2010) reviewed the building materials applicable to improve the built environment, materials for energy efficiency and thermal comfort in buildings. More than half of the total energy produced in the developed countries is used to improve inappropriate climate to reach thermal comfort levels for human beings. Usage of materials and passive technologies - strategies - in buildings would reduce the demand of energy consumption and carbon dioxide emissions in order to optimize the environmental behavior on built environment.

Jia Yin et al. [6] used various envelope insulation thicknesses to find out the optimal thickness. Also the optimal thickness for concrete exterior walls was carried out. Simulation of changing heat capacity proportion showed that the daily temperature difference decreased by 14 to $5.2^{\circ} \mathrm{C}$. Optimizing design of integrated building environment plays an important role in reducing energy consumption and improving thermal comfort. A passive solar house was taken as an example. A simulation proposed optimization design principles for passive solar house. 
Mohamed et al. [7] studied the effect of using different material specifications for the external walls on the cost of the energy consumption for achieving internal thermal comfort. In order to achieve indoor thermal comfort, a dynamic thermal simulation was carried out for four different types of external walls - commonly used in Egypt - in two different sets of cooling types: natural ventilation and mechanical means. Experiments recommend that using the Egyptian Residential Energy Code (EREC) to achieve inner thermal comfort with the minimum energy consumption (consequently the minimum $\mathrm{CO} 2$ emissions) and the minimum running cost as well.

Saeed [8] presents an attempt to define the overheated period for Bahrain and determine shading requirements and shading angles. From the results a special solar chart was drawn which provides accurate sun angle to use.

Waewsak et al. [9] indicate that the indoor environment is basically affected by the outdoor climate conditions; therefore, all built environment has a great task to protect the human from either the thermal mass stress or unsuitable indoor thermal condition. They presented a method for designing an innovative Bio-Climatic Roof (BCR) particularly suitable for hot and tropical climate intending to maximize residents' thermal comfort and minimize energy consumption of housing. The results indicated that, the BCR design can provide three important benefits: high ventilation rate, high insulating efficiency and sufficient lighting during daytime.

\section{Experimental work}

The building envelope affects the heat transfer through walls into the indoor zones. More dense materials pass more heat and light weight materials with low thermal conductivity resist the thermal energy. The present study describes field measurements of temperature for different rooms in a residential flat. The three rooms have different external walls construction.

\subsection{Case study description}

A residential flat (in Maadi district - Cairo - Egypt) of total area $180 \mathrm{~m}^{2}$ and height $3 \mathrm{~m}$, as shown in Fig. (1) consists of three bed rooms, living room, hall, kitchen, bath room and toilet was taken as a case study. The two bed rooms and the living room have the same area $\left(19.5 \mathrm{~m}^{2}\right)$ and same orientation façade (west direction). All of these rooms have the same brick wall construction with external finishes cement mortar. The three rooms differ in interior wall finishes.

The wall of the first room (living room) consist of hollow cement blocks of $20 \mathrm{~cm}$ thickness plastered with cement thickness $3 \mathrm{~cm}$ from outer side and $2 \mathrm{~cm}$ from inner side and painted with plastic material (as shown in sections Fig. 2-A ).

The second room (bed room) wall consists of hollow cement blocks with thickness $20 \mathrm{~cm}$ plastered with cement plaster for thickness $3 \mathrm{~cm}$ for outer side and $2 \mathrm{~cm}$ for inner side and painted, gladded with high density blue foam with thickness $5 \mathrm{~cm}$ inside wooden frame for $5 \mathrm{~cm}$ thickness then a layer of MDF (Medium Density Fiber) panels with $8 \mathrm{~mm}$ thickness fixed on the wooden frame and painted with plastic material (as shown in sections Fig. 2-B). 
The third room (bed room) wall consists of hollow cement blocks with thickness $20 \mathrm{~cm}$ plastered cement plaster for thickness $3 \mathrm{~cm}$ for outer side and gladded with natural stone (hashimi) with 4-5 cm thickness with $2 \mathrm{~cm}$ mortar thickness. (as shown in sections Fig. 2-C ).

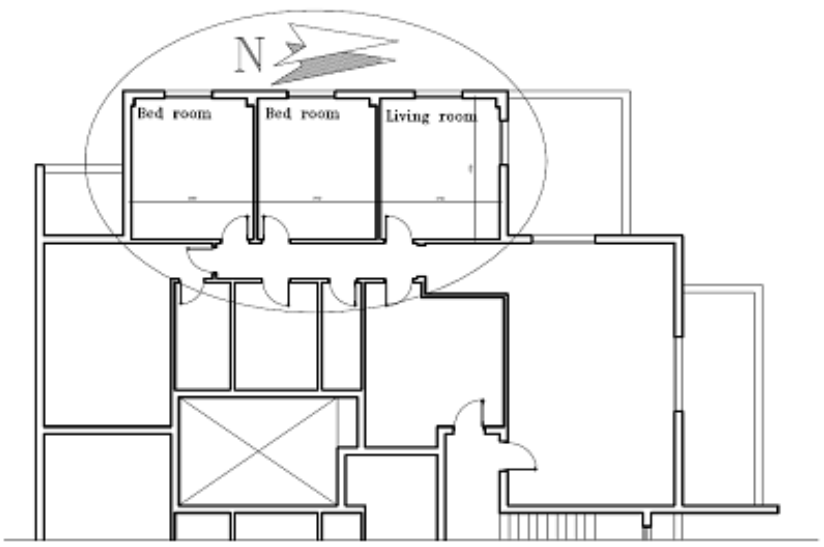

Fig. 1. Plan view of the tested flat

\section{2. Measuring techniques}

To study the effect of wall construction on the heat transfer and the thermal performance of the tested rooms, twelve thermocouples were fixed at different locations of the tested rooms, as shown in Fig.3 and photos in Fig.4 (a, b, c and d).

Point No. 1 to measure the outdoor air temperature (Tao).

point No. 2 to measure the external surface wall temperature (Tso).

Point No. 3 to measure the internal surface wall temperature (Tsi).

Point No. 4 to measure the indoor air temperature (Tai).

All of these 12 measuring points were taken at level $+1.5 \mathrm{~m}$ from floor level of the test area which is located on the fourth story in a five stories building, so the effect of the thermal mass produced from sun rays that affect on the roof is ignored because of the preservation of the above story from this thermal mass. The ceiling of the test flat is adiabatic.

In order to illustrate the heat performance through the temperature measurements which had been taken through 14 days (starting 24/7/2013, ending 6/8/2013) in the most hot months in Egypt (July \& August), measurements of just two days, (Thursday 25/7/2013 \& Thursday 1/8/2013) which were the hottest days in the test measurements period, had been recorded within tables ( as shown in tables 1, 2, and 3 ). So that 6 diagrams were drawn to illustrate the thermal behavior using insulation materials. Fourteen-day measurements were taken in the test period to assure the similarity of temperature behavior.

\section{3. Instrumentation}

All the thermocouples were connected to a scanning thermometer instrument to measure and record the temperature variation at different locations of the rooms during the tested days. Fig. 5 (a, b and c) shows photos of the scanning thermometer instrument. 


\section{Results and discussion}

The temperature distributions of the tested rooms were measured and recorded during a period of time from 25 July until 6 of August, which characterized with high solar radiation intensity, reaching nearly $900 \mathrm{~W} / \mathrm{m}^{2}$ and high outdoor air temperature.

Figure (6a-b) shows the temperature distribution of room 1 during days 25-7-2013 and 18-2013. The outdoor temperature reaches its maximum value nearly $39 \mathrm{C}^{\mathrm{O}}$ at hour 2:00 P.M. and the indoor temperature reaches its maximum value nearly $38.5 \mathrm{C}^{\circ}$ at hour 4:00 P.M. The time lag between the outdoor and indoor temperature is nearly 2 hours due to the high heat storage of the cement blocks. This increase in the indoor temperature is attributed to the increase of overall heat transfer coefficient (U-value) which nearly exceeds $1 \mathrm{~m}^{2} \mathrm{C}^{\mathrm{o}} / \mathrm{W}$. (OECP).

Figure (7 a-b) shows the temperature distribution of room 2 during days 25-7-2013 and 1-8-2013. The outdoor temperature reaches its maximum value nearly $39 \mathrm{C}^{\mathrm{o}}$ at hour 2:00 p.m. and the indoor temperature reaches its maximum value nearly $34 \mathrm{C}^{\circ}$ at hour 5:00 P.M. The time lag between the outdoor and indoor temperature is nearly 3 hours. The maximum indoor temperature of room 2 is lower than room 1 due to the presence of wall insulation. The overall heat transfer coefficient (U-value) is nearly $0.8 \mathrm{~m}^{2} \mathrm{C}^{\circ} / \mathrm{W}$ (OECP).

Figure ( 8 a-b) shows the temperature distribution of room 3 during days 25 July 2013 and $1^{\text {st }}$ August 2013. The outdoor temperature reaches its maximum value nearly $39^{\circ} \mathrm{C}$ at hour 2.00 p.m. and the indoor temperature reaches its maximum value nearly $33^{\circ} \mathrm{C}$ at hour 5:30 P.M. The time lag between the outdoor and indoor temperature is nearly 3.5 hours. The indoor wall and air temperatures of room 3 give lower values during the day in comparison of room 1 and room 2 due to the lower magnitude of $U$-value nearly $0.7 \mathrm{~m}^{2} \mathrm{C}^{\mathrm{o}} / \mathrm{W}$.

Line no.1 (navy blue) illustrates the outdoor air temperature (Tao).

Line no.2 (magenta) illustrates the outer side of the outdoor wall temperature (Tso).

Line no.3 (orange) illustrates the inner side of the outdoor wall temperature (Tsi).

Line no.4 (green) illustrates the indoor air temperature (Tai).

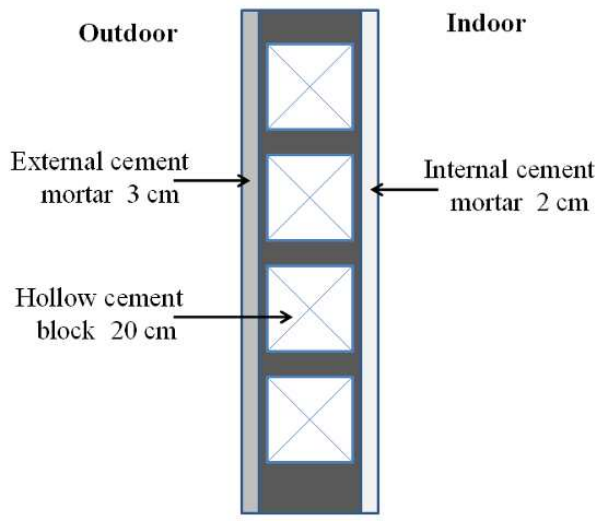

(a) External wall of room (1) 


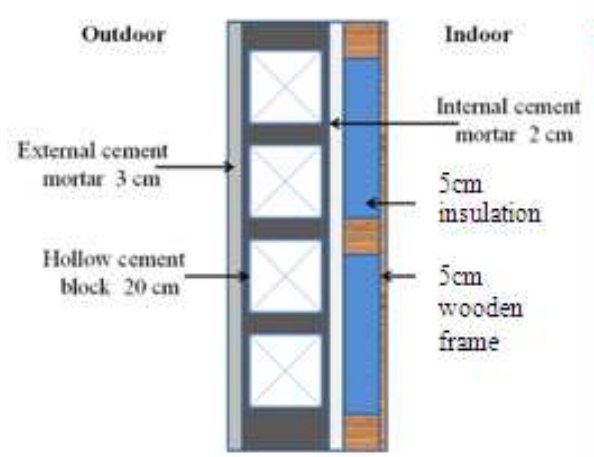

(b) External wall of room (2)

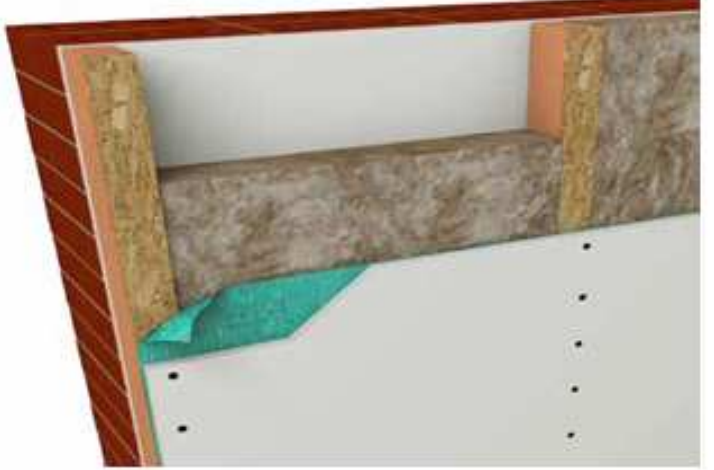

Example of the existing wall and insulation
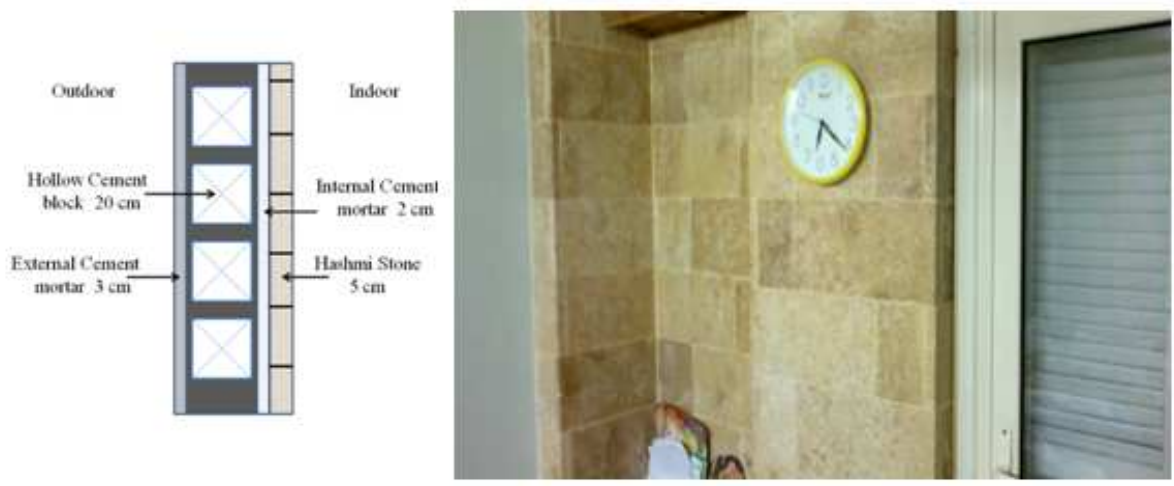

(c) External wall of room (3)

current wall and hashimi stone

Fig. 2. (a, b, c) External wall construction for the three test rooms.

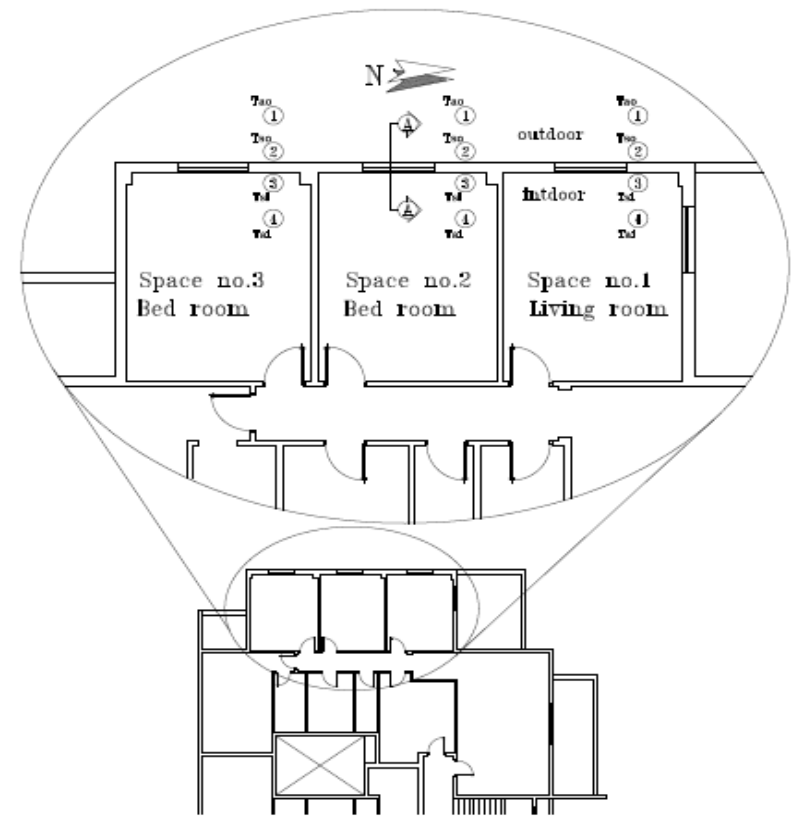

Fig. 3. Location of thermocouples for temperature measurements 
Wael Ahmad Taha EL-Garhy, The effect of using insulation materials on the thermal..........

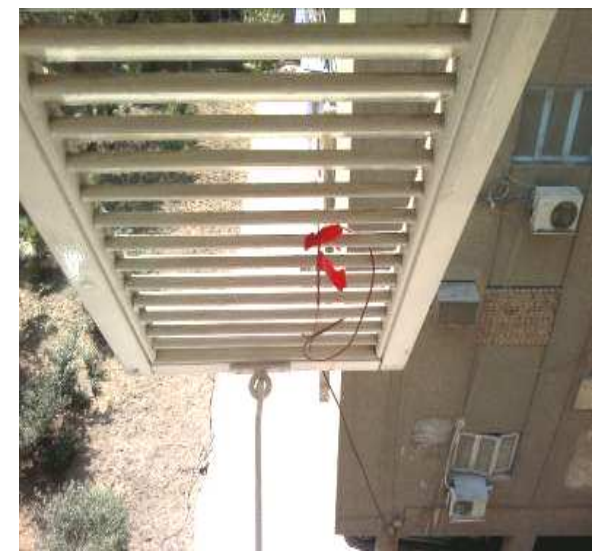

(a) Point No. 1

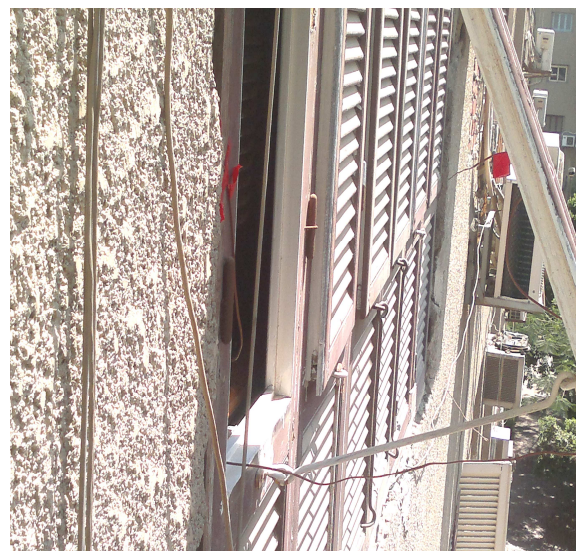

(b) Point No. 2

To measure the outdoor air temperature (Tao). To measure the outdoor air temperature

The thermocouple fixed to keep the end of it free in the outdoor air and keep it in shadow

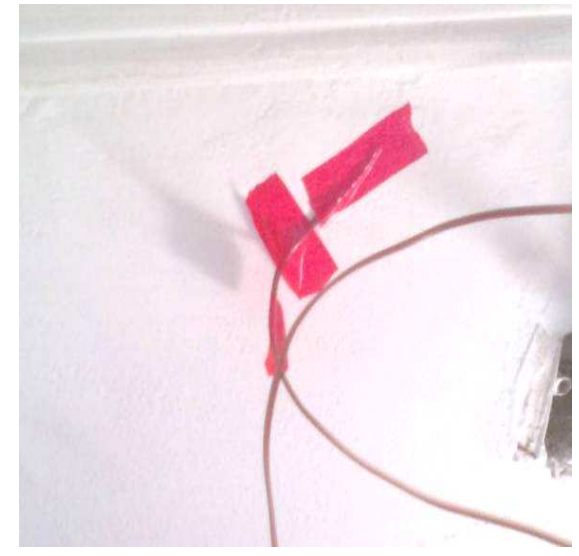

(c) Point No. 3
The thermocouple fixed to keep the end of it contiguous to the external surface of the external wall and keep it in shadow

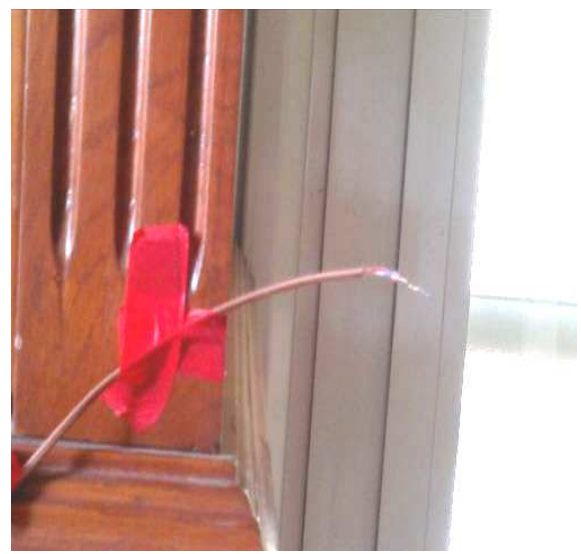

(d) Point No. 4

to measure the outdoor air temperature (Tsi). to measure the outdoor air temperature (Tai) The thermocouple fixed to keep the end of it contiguous to the internal surface of the external wall and keep it in shadow

The thermocouple fixed to keep the end of it free in the indoor air and keep it in shadow

Fig. 4. (a, b, c, d) Thermocouple locations at the tested rooms.

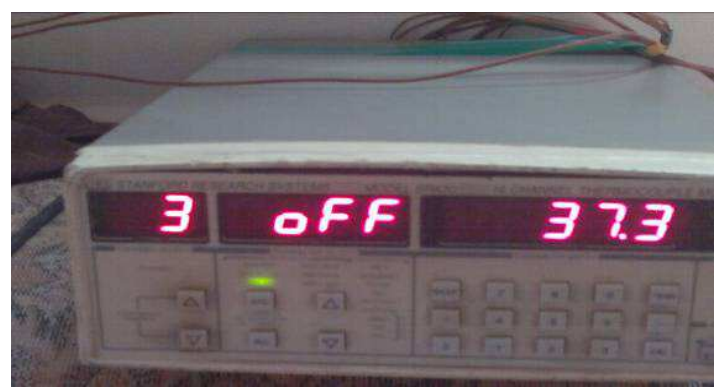

(a) The front façade of the scanning thermometer instrument 


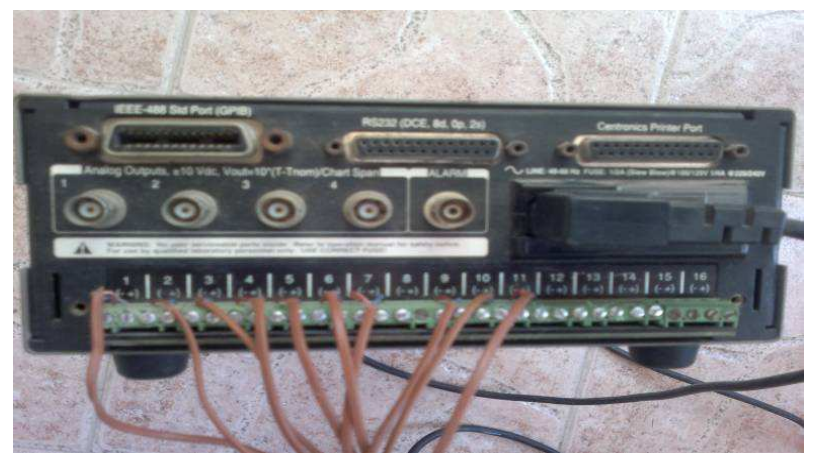

(b) The back façade of the scanning thermometer instrument illustrates the joint sockets

(c) The 12 thermocouples connected between the scanning thermometer instrument sockets and measuring points

Fig. 5. (a, b, c) Temperature scanning and recording instrument (16 channel)

Table 1.

Observation of temperature levels for room No. 1

\begin{tabular}{|c|c|c|c|c|}
\hline Hour & Tao & Tso & Tsi & Tai \\
\hline 1 & 31.7 & 31.6 & 33.0 & 33.8 \\
\hline 2 & 30.6 & 30.6 & 31.9 & 32.0 \\
\hline 3 & 29.5 & 29.5 & 30.3 & 30.4 \\
\hline 4 & 28.5 & 28.5 & 28.9 & 29.2 \\
\hline 5 & 28.6 & 27.9 & 28.0 & 28.7 \\
\hline 6 & 28.7 & 27.3 & 27.2 & 28.1 \\
\hline 7 & 29.0 & 28.3 & 27.5 & 30.0 \\
\hline 8 & 30.3 & 29.4 & 27.9 & 30.5 \\
\hline 9 & 31.3 & 31.2 & 31.0 & 31.1 \\
\hline 10 & 32.8 & 31.4 & 32.0 & 31.8 \\
\hline 11 & 35.0 & 33.6 & 33.8 & 32.2 \\
\hline 12 & 37.1 & 35.9 & 35.6 & 33.4 \\
\hline 13 & 39.2 & 38.2 & 37.5 & 36.0 \\
\hline 14 & 39.5 & 39.0 & 38.5 & 36.8 \\
\hline 15 & 39.1 & 39.1 & 38.9 & 37.8 \\
\hline 16 & 38.8 & 39.3 & 39.2 & 38.9 \\
\hline 17 & 38.5 & 39.0 & 39.6 & 39.2 \\
\hline 18 & 37.3 & 38.5 & 39.0 & 38.7 \\
\hline
\end{tabular}


Wael Ahmad Taha EL-Garhy, The effect of using insulation materials on the thermal..........

\begin{tabular}{|c|c|c|c|c|}
\hline Hour & Tao & Tso & Tsi & Tai \\
\hline 19 & 35.6 & 38.0 & 37.7 & 37.1 \\
\hline 20 & 34.1 & 37.4 & 37.3 & 35.8 \\
\hline 21 & 33.2 & 36.5 & 37.1 & 35.8 \\
\hline 22 & 32.3 & 34.8 & 36.8 & 35.7 \\
\hline 23 & 32.5 & 33.0 & 36.4 & 35.5 \\
\hline 24 & 32.1 & 32.3 & 34.9 & 34.7 \\
\hline
\end{tabular}
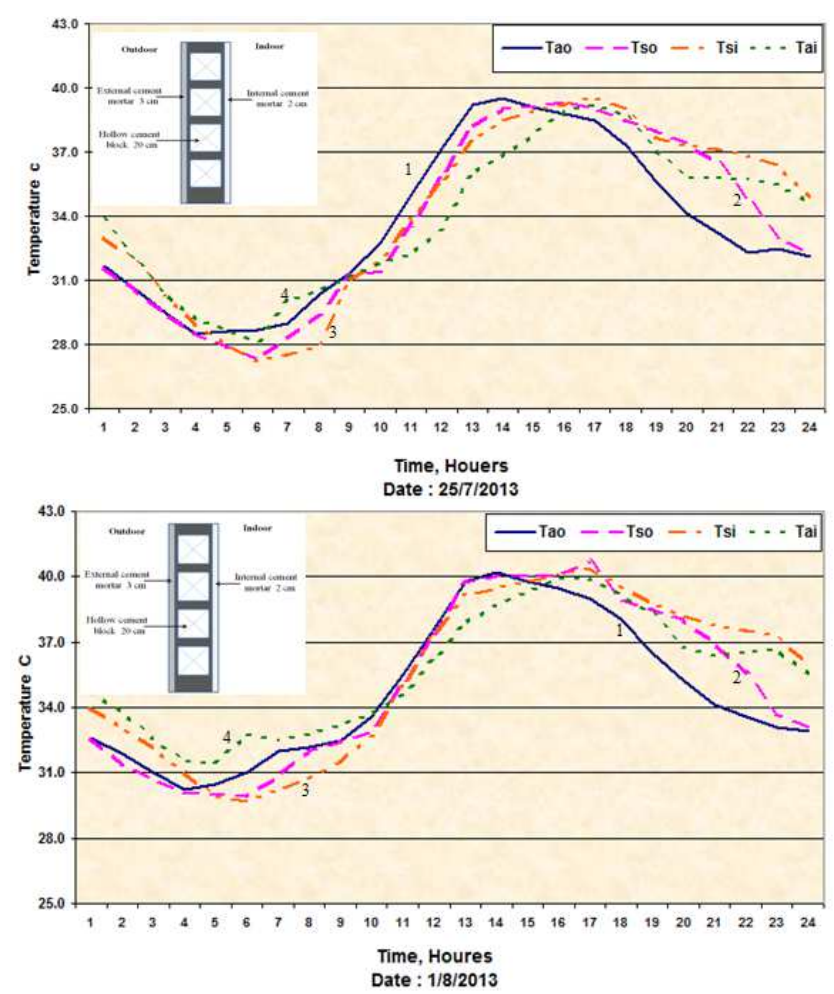

Fig. 6. Temperature distribution for room (1)

Table 2.

Observation of temperature levels for room No. 2

\begin{tabular}{|c|c|c|c|c|}
\hline Hour & Tao & Tso & Tsi & Tai \\
\hline 1 & 31.7 & 32.7 & 31.4 & 31.5 \\
\hline 2 & 30.6 & 31.6 & 30.8 & 30.5 \\
\hline 3 & 29.5 & 29.6 & 30.4 & 29.8 \\
\hline 4 & 28.5 & 28.7 & 30.0 & 29.1 \\
\hline 5 & 28.6 & 28.0 & 29.7 & 29.1 \\
\hline 6 & 28.7 & 27.4 & 29.2 & 29.1 \\
\hline 7 & 29.0 & 28.4 & 29.4 & 30.0 \\
\hline 8 & 30.3 & 29.4 & 29.7 & 31.0 \\
\hline 9 & 31.3 & 31.2 & 31.5 & 31.5 \\
\hline 10 & 32.8 & 31.4 & 31.5 & 31.5 \\
\hline 11 & 35.9 & 33.6 & 32.0 & 32.0 \\
\hline 12 & 37.1 & 35.9 & 32.5 & 32.5 \\
\hline 13 & 39.2 & 38.2 & 33.1 & 33.0 \\
\hline 14 & 39.5 & 39.0 & 33.2 & 33.0 \\
\hline
\end{tabular}


JES, Assiut University, Faculty of Engineering, Vol. 42, No. 4, July 2014, pp. 1080-1093

\begin{tabular}{|c|c|c|c|c|}
\hline Hour & Tao & Tso & Tsi & Tai \\
\hline 15 & 39.1 & 39.1 & 33.2 & 33.1 \\
\hline 16 & 38.8 & 39.3 & 33.2 & 33.3 \\
\hline 17 & 38.5 & 40.2 & 33.2 & 33.3 \\
\hline 18 & 37.3 & 39.8 & 33.0 & 33.1 \\
\hline 19 & 35.6 & 38.2 & 33.0 & 33.0 \\
\hline 20 & 34.1 & 37.8 & 32.7 & 33.0 \\
\hline 21 & 33.2 & 37.3 & 32.5 & 32.4 \\
\hline 22 & 32.3 & 35.5 & 32.3 & 32.1 \\
\hline 23 & 32.5 & 33.7 & 31.9 & 31.9 \\
\hline 24 & 32.1 & 33.3 & 31.7 & 31.7 \\
\hline
\end{tabular}
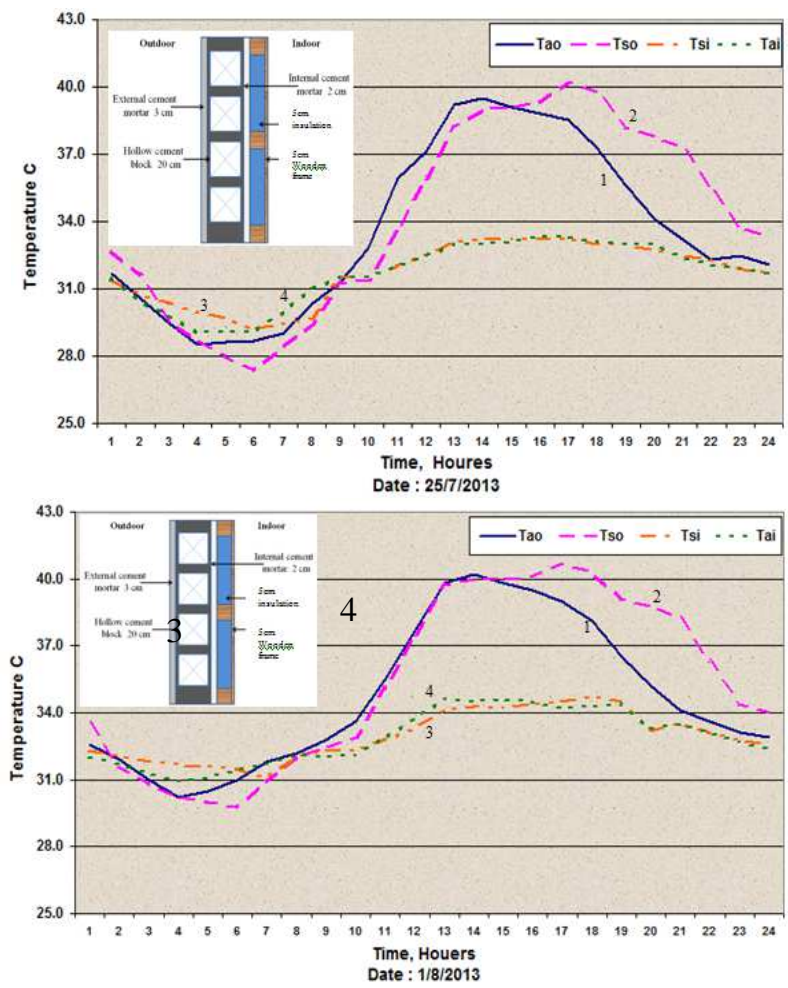

Fig. 7. Temperature distribution for room (1)

Table 3.

Observation of temperature levels for room No. 3

\begin{tabular}{|c|c|c|c|c|}
\hline Hour & Tao & Tso & Tsi & Tai \\
\hline 1 & 31.7 & 32.3 & 31.3 & 31.3 \\
\hline 2 & 30.6 & 31.2 & 30.5 & 30.4 \\
\hline 3 & 29.5 & 29.4 & 29.8 & 29.7 \\
\hline 4 & 28.5 & 28.7 & 29.2 & 29.0 \\
\hline 5 & 28.6 & 28.1 & 28.7 & 29.1 \\
\hline 6 & 28.7 & 27.8 & 28.2 & 29.2 \\
\hline 7 & 29.0 & 28.5 & 28.2 & 29.3 \\
\hline 8 & 30.3 & 29.4 & 28.3 & 29.7 \\
\hline 9 & 31.3 & 31.3 & 30.6 & 30.7 \\
\hline 10 & 32.8 & 31.4 & 30.6 & 30.7 \\
\hline
\end{tabular}


Wael Ahmad Taha EL-Garhy, The effect of using insulation materials on the thermal..........

\begin{tabular}{|l|l|l|l|l|}
\hline 11 & & & 31.5 & 31.6 \\
\hline 12 & 35.9 & 33.6 & 32.4 & 32.4 \\
\hline 13 & 37.1 & 35.9 & 33.3 & 33.3 \\
\hline 14 & 39.2 & 38.2 & 33.4 & 33.3 \\
\hline 15 & 39.5 & 39.0 & 33.4 & 33.3 \\
\hline 16 & 39.1 & 39.1 & 33.4 & 33.4 \\
\hline 17 & 38.8 & 39.3 & 33.4 & 33.4 \\
\hline 18 & 38.5 & 40.1 & 33.3 & 33.2 \\
\hline 19 & 37.3 & 39.2 & 33.2 & 33.1 \\
\hline 20 & 35.6 & 38.0 & 32.8 & 32.9 \\
\hline 21 & 34.1 & 37.4 & 32.3 & 32.4 \\
\hline 22 & 33.2 & 37.0 & 32.0 & 32.1 \\
\hline 23 & 32.3 & 35.6 & 31.7 & 31.8 \\
\hline 24 & 32.5 & 34.0 & 31.5 & 31.6 \\
\hline
\end{tabular}
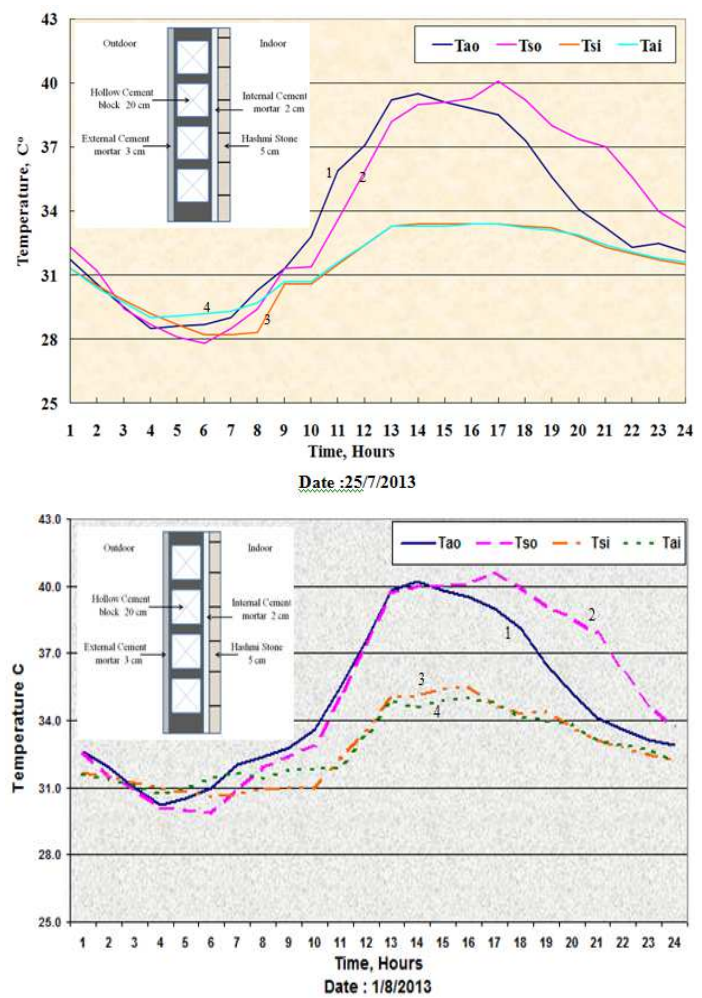

Fig. 8. Temperature distribution for room (3)

\section{Conclusion}

From previous results we can conclude that:

1) Good building insulation offers favorable and comfortable indoor environment natural condition without using of any mechanical devices (such as electric fans or A/C system). Therefore, the good insulation for roofs and sunny façades, to maintain acceptable level of the indoor thermal comfort is quite sufficient because they are the most important building elements continuously exposed to the sky dome. So, roofs and sunny walls insulation is very important in both design and construction processes of the building. 
2) Previous results confirmed that sunny walls are major parts of building that must be carefully studied under the climatic conditions. The effect of the shading devices on the total energy consumption is small because the shading devices are used only for the openings (windows or balconies) but the solid parts of the building are still under the exposed to the direct and indirect solar radiation.

3) Good type of Insulation is the simplest and most common way to protect the indoors from uncomfortable weather and plays an important role in effective treatment, however, the wrong type of insulation can work against human thermal comfort by blocking heat when needed to retain it and vice-versa. Walls that are designed in response to the climate, with an appropriate thermal mass and the right kind of insulation will keep indoor space comfortable, lower heating and cooling costs and preserve natural resources.

4) External walls allow much heat exchange between the indoor envelope of a house and the outdoor. As well as acting as a primary insulation layer, the inner part of an external wall can also be used to store energy, but this can only be achieved with compound wall construction where the outside warm wall is separated from the inside cold wall by insulation. External walls fall into three basic categories: low thermal mass, medium thermal mass and high thermal mass.

5) Although the insulation for external side of the external wall with appropriate materials is more effective several times than the insulation for internal side for the same wall, this work concerned with the effect of the internal side insulation of the external wall on the thermal performance of the building envelope for some reasons:

- When the external side is not accessible.

- The insulating material in the internal position of the building has a great effects on reducing consumption of energy by preventing the leakage of high temperature or thermal mass from hot outer ambient to the inner spaces in insulated buildings in summer.

- Vice versa, in winter to keep thermal mass inside buildings and prevent losing it through its leakage through non insulated walls.

6) A cost analysis has to be done in comparison between the cost of achieving thermal comfort for occupants by using mechanical means and between using insulation (cheep or expensive) materials taking in consideration the energy running cost and maintenance, advantages and disadvantages of using natural materials and consumption of natural resources (benefit and exploitation) for a long term.

7) A healthy analysis has to be done comparing two factors:

- Emissions of using passive strategies - energy consumer means.

- Side effects of using radiological (or non radiological) manufactured and artificial insulation materials for short and long terms. 


\section{REFERENCES}

[1] Al-Karagholi, A.; Aboud, I. and Amin, I. (2000). Evaluation of energy conservation techniques of a solar air conditioned house, the Workshop on Energy Conservation in Industrial Applications, 12-14 February, Dhahran, Saudi Arabia, 2000 (Proceeding)

[2] Chang Feng Wang and Guo Qiang Fan (2013). Unscrambling the Building Envelope Insulation Technique in: Tianjin Energy Efficiency Design Standard for Rural Residential Buildings, Advanced Materials Research, Volumes (805 - 806): 1519-1523. http://www.scientific.net/AMR.805-806.1519

[3] Chwieduk, D. (2002). Traditional and Modern Options for Energy Conservation in Buildings. WREC VII, Germany (Proceedings).

[4] Hai-xiang Zhao and Frederic Magoules (2012). A review on the prediction of building energy consumption. Renewable and Sustainable Energy Reviews, 16 (6) : 3586-3592.

[5] Hall M. Prix (2010). Materials for energy efficiency and thermal comfort in buildings Auteur. Indicatif, 219,86 : 734 p. (C) 2013 LAVOISIER S.A.S.

[6] Jia Yin Zhu et al. (2013). Optimization of Building Envelope Thermal Design for Passive Solar House. Applied Mechanics and Materials, 368-370, 1250.

[7] Mohamed M. Mahdy et al. (2013). From Construction to Operation: Achieving Indoor Thermal Comfort via Altering External Walls Specifications in Egypt. Advanced Materials Research, 689, 250 -253. cited at http://www.scientific.net/AMR.689.250.

[8] Saeed, S. A. R. (2002). Solar Radiation Protection Strategies for Building in Bahrain. WREC VII, Germany (Proceedings).

[9] Waewsak, J. ; Hirunlabh, J.; Khedari, J. and Zeghmati, B.A. (2002). Bio-climatic roof for hot and humid climate: design approach. World Renewable Energy Congress, WREC VII, Germany (Proceedings).

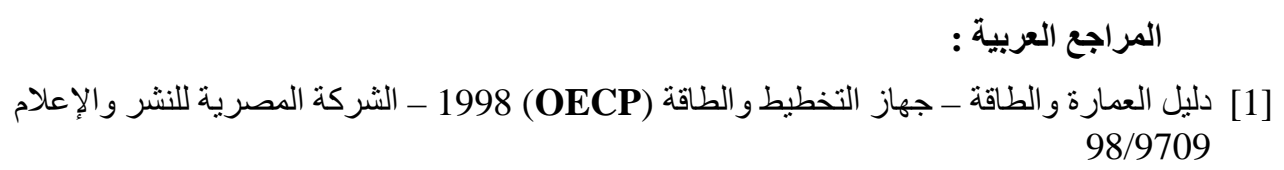

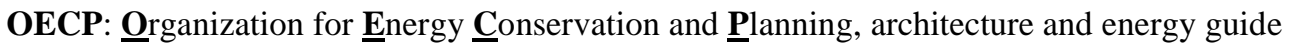




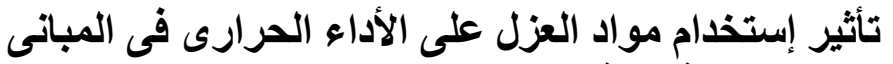 دراسة حالة لمبنى سكنى بالقاهرة ـ مصر فر الأل}

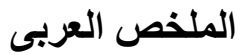

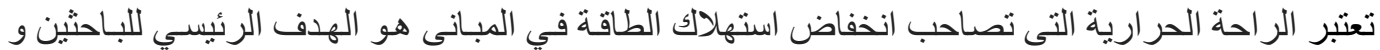

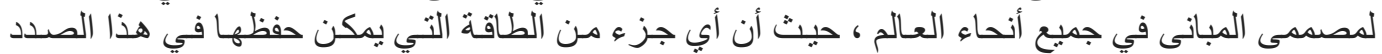

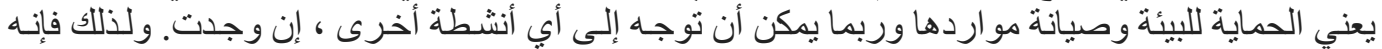

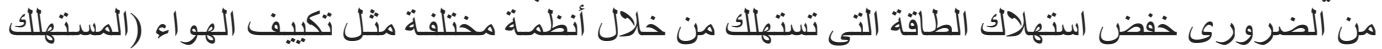

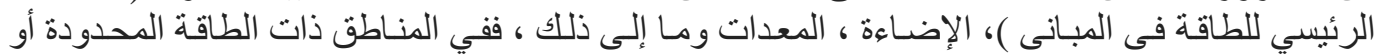

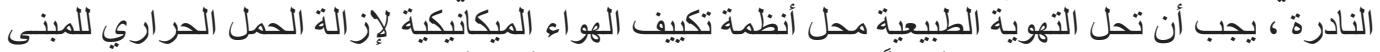

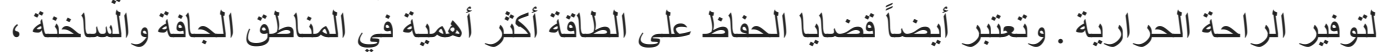

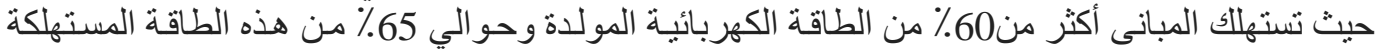
للتبريد. حيد.

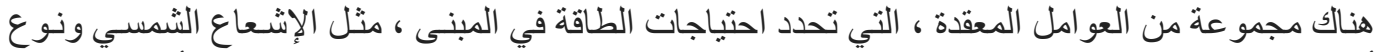

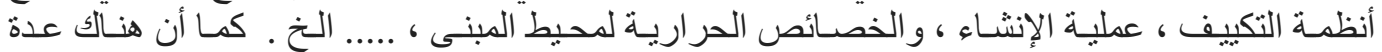

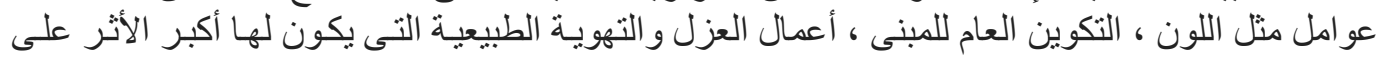

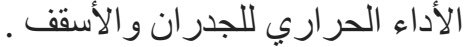

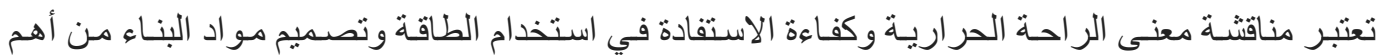

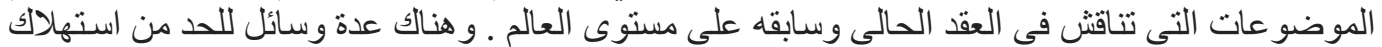

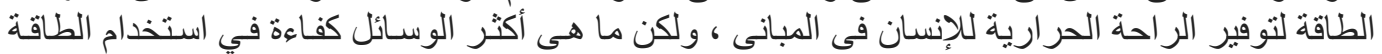

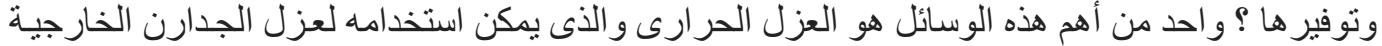

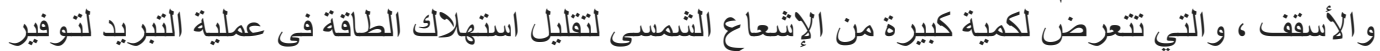

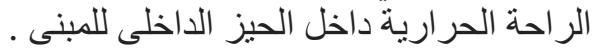

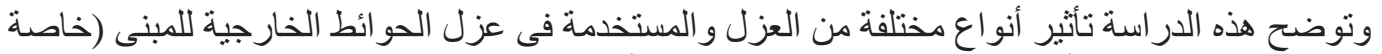

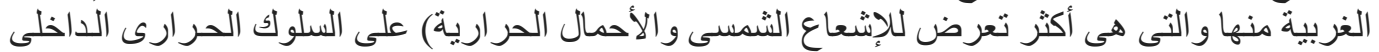

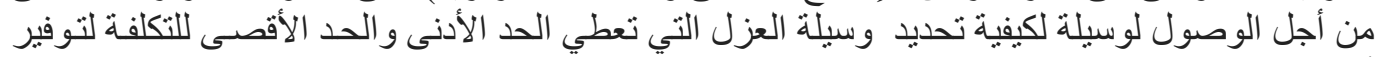

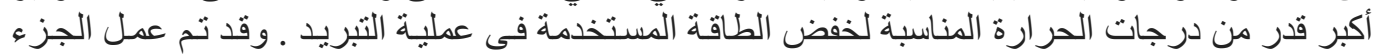

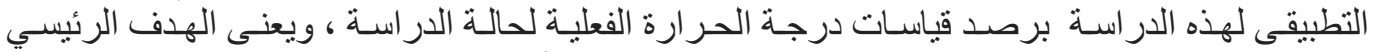

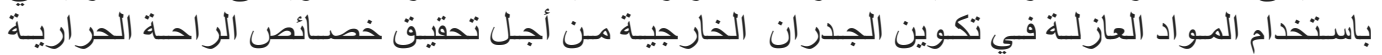

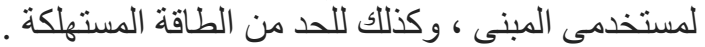

كلمات البحث •. الكتلة الحر ارية ـ الر احة الحرارية ـ مو اد العزل ـ حفظ الطاقة ـ استهلاك الطاقة 